\title{
Large Eddy Simulations of the Ceiling Jet Induced by the Impingement of a Turbulent Air Plume
}

\author{
Setareh Ebrahim Zadeh*, Georgios Maragkos, Tarek Beji and Bart \\ Merci, Department of Flow, Heat and Combustion Mechanics, Ghent \\ University, Sint-Pietersnieuwstraat 41, 9000 Ghent, Belgium
}

Received: 9 July 2015/Accepted: 30 December 2015

\begin{abstract}
In this paper, a sensitivity study is performed with FireFOAM 2.2.x for a hot air jet plume impinging onto a flat horizontal ceiling. The plume evolution and the induced ceiling flow are considered. The influence of the level of turbulence imposed at the inlet, in terms of intensity and eddy length scale, is discussed. Also, the effect of the turbulence model constant is examined. For the case considered, the best results are obtained when no sub-grid scale (SGS) model is used. If a SGS model is used, the level of turbulence at the inlet and the choice of the turbulence model constant are shown to have a significant effect on the prediction of plume's spreading and the ceiling flow velocity. The eddy length scale at the inflow does not have significant impact on the results. Comparisons with the available experimental data indicate that FireFOAM is capable of predicting the mean velocity-field well. In the near field region, an under-estimation of the turbulent velocity fluctuations is observed, whereas reasonably good agreement is obtained in the far field.
\end{abstract}

Keywords: FireFOAM, Hot air jet plume, Ceiling flow, LES

\section{List of Symbols}

$T \quad$ Temperature $\left({ }^{\circ} \mathrm{C}\right)$

Re Reynolds number (-)

$u \quad$ Velocity $(\mathrm{m} / \mathrm{s})$

$v \quad$ Velocity $(\mathrm{m} / \mathrm{s})$

$D \quad$ Diameter (m)

$\mathrm{Fr} \quad$ Froude number (-)

$g \quad$ Gravitational acceleration $\left(\mathrm{m} / \mathrm{s}^{2}\right)$

$k \quad$ Turbulent kinetic energy $\left(\mathrm{m}^{2} / \mathrm{s}^{2}\right)$

$p \quad$ Pressure $(\mathrm{Pa})$

$Y \quad$ Mass fraction (-)

$D_{k} \quad$ Molecular diffusivity $\left(\mathrm{m}^{2} / \mathrm{s}\right)$

$D_{t h} \quad$ Thermal diffusivity $\left(\mathrm{m}^{2} / \mathrm{s}\right)$

$\mathrm{Pr} \quad$ Prandtl number (-)

$h_{s} \quad$ Sensible enthalpy $(\mathrm{J} / \mathrm{kg})$

$c_{k} \quad$ One-equation turbulence model constant (-)

* Correspondence should be addressed to: Setareh Ebrahim Zadeh, E-mail: setareh.ebrahimzadeh@ ugent.be 
$c_{s} \quad$ Smagorinsky model constant (-)

$S \quad$ Strain rate $\left(\mathrm{s}^{-1}\right)$

$z \quad$ Height $(\mathrm{m})$

$r \quad$ Radial distance $(\mathrm{m})$

\section{Greek}

$\begin{array}{ll}\rho & \text { Density }\left(\mathrm{kg} / \mathrm{m}^{3}\right) \\ \mu & \text { Dynamic viscosity }(\mathrm{kg} /(\mathrm{m} \mathrm{s})) \\ v & \text { Kinematic viscosity }\left(\mathrm{m}^{2} / \mathrm{s}\right) \\ \varepsilon & \text { Turbulent dissipation rate }\left(\mathrm{m}^{2} / \mathrm{s}^{3}\right) \\ \delta_{v} & \text { Viscous sublayer }(\mathrm{mm}) \\ \delta_{i j} & \text { Kronecker delta }(-)\end{array}$

\section{Subscripts}

i Inlet

m Maximum

$\infty \quad$ Ambient

$t \quad$ Turbulent

\section{Superscripts}

Fluctuations

\section{Introduction}

In a compartment fire, hot gases rising from a burning fuel travel upwards due to buoyancy and momentum, impinge onto the ceiling and then spread out radially as a ceiling jet. The impingement of a hot gas plume or jet on the ceiling is an important aspect in fire safety engineering due to its influence on the activation of ceiling-mounted detection devices and automatic sprinklers. In order to have a good prediction of ceiling-jet flows, accurate modeling of the turbulent plume structure is required.

Buoyant plumes have been the subject of various experimental and numerical studies in the past. Mean and turbulence quantities for a free axi-symmetric hot air turbulent plume were studied experimentally in [1, 2]. Both the Reynolds Averaged Navier-Stokes (RANS) [3] and the Large Eddy Simulation (LES) approaches [4-9] have been used in simulations of turbulent buoyant plumes. In $[10,11]$ a reduced-scale experiment of a hot air plume beneath a ceiling with three different convective heat release rates was conducted. Mean and turbulent velocities were measured in the plume and in the ceiling jet. Substantial work has also been dedicated to the ceiling jet dynamics, discussing the velocities, temperature rises, and thicknesses of steady fire-driven ceiling jet flows in [11-15].

It is clear that in the application of LES to turbulent plumes there are many influencing factors that can have significant effects on the predicted results, such as the choice of the sub-grid models, the model constants and the imposed inflow boundary conditions. In the present work, LES simulations of a ceiling jet induced by the impingement of a turbulent hot air jet plume are performed using 
FireFOAM 2.2.x [16] and the results are compared to experimental data. The objective of this paper is to simulate a turbulent jet plume using LES, aiming at obtaining a clearer picture of the influencing factors on the plume's evolution and the induced ceiling-jet. Therefore, the structure of the hot air plume and the velocities near the ceiling at different radial locations are numerically investigated by mainly addressing the influence of:

1. The inflow boundary condition,

2. The size of eddies at the inlet, and

3. The turbulence model constant.

This study is part of a larger research project regarding the investigation of the interaction between water sprays, plumes and ceiling layer flows [10].

\section{Test Case}

The case considered is the hot air jet plume experiments carried out by Zhou [10, 11]. They were performed in order to extend the existing studies of the interaction between hot air plumes and water sprays, specifically regarding the influence of the water sprays on the induced ceiling flows driven by strong plumes (from, e.g. rack storage fires).

The test consists of a $72 \mathrm{~mm}$ diameter nozzle, providing a hot air source, with an aluminum ceiling plate with dimensions of $1.22 \mathrm{~m} \times 1.22 \mathrm{~m}$ placed at height $590 \mathrm{~mm}$ above the nozzle. Hot air with a temperature of $205^{\circ} \mathrm{C}$ is issued through the nozzle. The ambient temperature is $T_{\infty}=20^{\circ} \mathrm{C}$. A range of hot airflows are generated by changing the exit velocity and maintaining a constant exit air temperature. The measured convective heat release rates (HRRs) are $1.6 \mathrm{~kW}, 2.1 \mathrm{~kW}$ and $2.6 \mathrm{~kW}$, corresponding to the maximum exit velocity of $3.3 \mathrm{~m} / \mathrm{s}, 4.2 \mathrm{~m} / \mathrm{s}$ and $5.3 \mathrm{~m} / \mathrm{s}$, respectively. A more detailed description of the experimental set-up can be found in $[10,11]$.

The Reynolds number $R e=\frac{\rho v_{i} D}{\mu}$ and Froude number $F r=\frac{v_{i}^{2}}{g D}$ for the three cases are also listed in Table 1. Note that for all cases the Froude number is intermediate compared to typical values for natural fire (order 1 and lower) and momentum-driven jets (where the Froude number can be in the order of 10,000 or higher) [17].

\section{Table 1}

Flow Parameters at the Inlet

\begin{tabular}{lccccc}
\hline $\mathrm{D}(\mathrm{m})$ & $\mathrm{Q}_{\text {conv. }}(\mathrm{kW})$ & $\mathrm{v}_{\mathrm{i}, \max }(\mathrm{m} / \mathrm{s})$ & $\mathrm{T}_{\mathrm{i}}\left({ }^{\circ} \mathrm{C}\right)$ & $\mathrm{Re}$ & $\mathrm{Fr}$ \\
\hline 0.072 & 2.6 & 5.3 & 205 & 11,000 & 39.8 \\
0.072 & 2.1 & 4.2 & 205 & 8700 & 25 \\
0.072 & 1.6 & 3.3 & 205 & 6800 & 15.4 \\
\hline
\end{tabular}




\section{Numerical Modeling}

FireFOAM (version 2.2.x), is a CFD package based on the OpenFOAM [18] platform. It is an LES code with various models for turbulence, radiation, combustion, and pyrolysis.

In the gas phase, FireFOAM solves the Favre filtered transport equations of mass, momentum, species and sensible enthalpy:

$$
\begin{aligned}
& \frac{\partial \bar{\rho}}{\partial t}+\frac{\partial\left(\bar{\rho} \tilde{u}_{j}\right)}{\partial x_{j}}=0 \\
& \frac{\partial\left(\bar{\rho} \tilde{u}_{i}\right)}{\partial t}+\frac{\partial\left(\bar{\rho} \tilde{u}_{i} \tilde{u}_{j}\right)}{\partial x_{j}}=\frac{\partial}{\partial x_{j}}\left(\bar{\rho}\left(v+v_{t}\right)\left(\frac{\partial \tilde{u}_{i}}{\partial x_{j}}+\frac{\partial \tilde{u}_{j}}{\partial x_{i}}-\frac{2}{3} \frac{\partial \tilde{u}_{k}}{\partial x_{k}} \delta_{i j}\right)\right)-\frac{\partial \bar{p}}{\partial x_{i}}+\bar{\rho} g_{i} \\
& \frac{\partial\left(\bar{\rho} \tilde{Y}_{k}\right)}{\partial t}+\frac{\partial\left(\bar{\rho} \tilde{u}_{j} \tilde{Y}_{k}\right)}{\partial x_{j}}=\frac{\partial}{\partial x_{j}}\left(\bar{\rho}\left(D_{k}+\frac{v_{t}}{\operatorname{Pr}_{t}}\right) \frac{\partial \tilde{Y}_{k}}{\partial x_{j}}\right) \\
& \frac{\partial\left(\bar{\rho} \tilde{h}_{s}\right)}{\partial t}+\frac{\partial\left(\bar{\rho} \tilde{u}_{j} \tilde{h}_{s}\right)}{\partial x_{j}}=\frac{D \bar{p}}{D t}+\frac{\partial}{\partial x_{j}}\left(\bar{\rho}\left(D_{t h}+\frac{v_{t}}{\operatorname{Pr}_{t}}\right) \frac{\partial \tilde{h}_{s}}{\partial x_{j}}\right)
\end{aligned}
$$

where $\rho$ is the density, $u$ is the velocity, $p$ is the pressure, $v_{t}$ is the turbulent kinematic viscosity, $g_{i}$ is the gravitational acceleration, $Y_{k}$ is the mass fraction of species $k, D_{k}$ is the molecular diffusivity, $h_{s}$ is the sensible enthalpy, $D_{t h}$ is thermal diffusivity, $\operatorname{Pr}_{t}$ is turbulent Prandtl number and $\delta_{i j}$ is the Kronecker delta.

Turbulence is modeled by the one-equation eddy viscosity model [19], one of the most often used turbulence model in FireFOAM, in which a transport equation for the sub-grid scale kinetic energy, $k$, is solved:

$$
\frac{\partial(\bar{\rho} k)}{\partial t}+\nabla(\bar{\rho} \tilde{u} k)=\nabla\left[\left(\mu+\frac{\mu_{t}}{S c_{t}}\right) \nabla k\right]+P-\bar{\rho} \varepsilon
$$

The turbulent viscosity, $\mu_{t}$, is then calculated as:

$$
\mu_{t}=\bar{\rho} c_{k} \Delta k^{1 / 2}
$$

where $\Delta$ is the filter width calculated as the cubic root of the cell volume and $c_{k}$ is a model parametric taken as constant (e.g., $c_{k}=0.05$ [20] or $c_{k}=0.07$ [21]).

The production rate of the sub-grid scale kinetic energy, $P$, is calculated as:

$$
P=-\frac{2}{3}\left(\bar{\rho} k+\mu \frac{\partial \tilde{u}_{k}}{\partial x_{k}}\right) \frac{\partial \tilde{u}_{i}}{\partial x_{i}}+2 \mu \frac{\partial \tilde{u}_{i}}{\partial x_{j}} \frac{\partial \tilde{u}_{j}}{\partial x_{i}}
$$


The dissipation rate, $\varepsilon$, is expressed as:

$$
\varepsilon=c_{\varepsilon} k^{3 / 2} \Delta^{-1}
$$

with $c_{\varepsilon}$ a dimensionless model coefficient $\left(c_{\varepsilon}=1.048[21]\right)$.

\subsection{Discretization Schemes}

A first-order implicit scheme is used for temporal discretization. In the convection terms, a second-order central differencing for the velocity and a second-order TVD scheme for the scalars are used. A second-order central difference scheme with non-orthogonal corrections is used for the diffusion terms [18].

\section{Computational Set-Up}

The computational domain is $2 \mathrm{~m} \times 2 \mathrm{~m} \times 0.734 \mathrm{~m}$. It is extended by $0.4 \mathrm{~m}$ at each side of the ceiling. An 'open' boundary condition is employed at the sides, bottom and the extended parts on top of the computational domain. At the ceiling, a zero gradient boundary condition is applied for the sub-grid scale viscosity in addition to the no-slip boundary condition for the velocity. Due to the good grid resolution near the wall, no specific turbulent wall treatment is considered for the ceiling B.C.

An unstructured Cartesian computational mesh, shown in Figure 1, is used in the simulations. It has been generated using OpenFOAM's mesh generation utility snappyHexMesh [22]. The total number of cells is 7 million, with 14 cells across the jet inlet, as shown in Figure 2. This corresponds to a mesh size of $5 \mathrm{~mm}$. Mesh refinement is applied in the region of the thermal plume and the ceiling layer flow. The grid is also refined in the region near the ceiling with a minimum wall-normal spacing of $\Delta \mathrm{z}=2 \mathrm{~mm}$. The numerical simulations are run for $20 \mathrm{~s}$ of real time. Averaging is done over the last $17 \mathrm{~s}$.

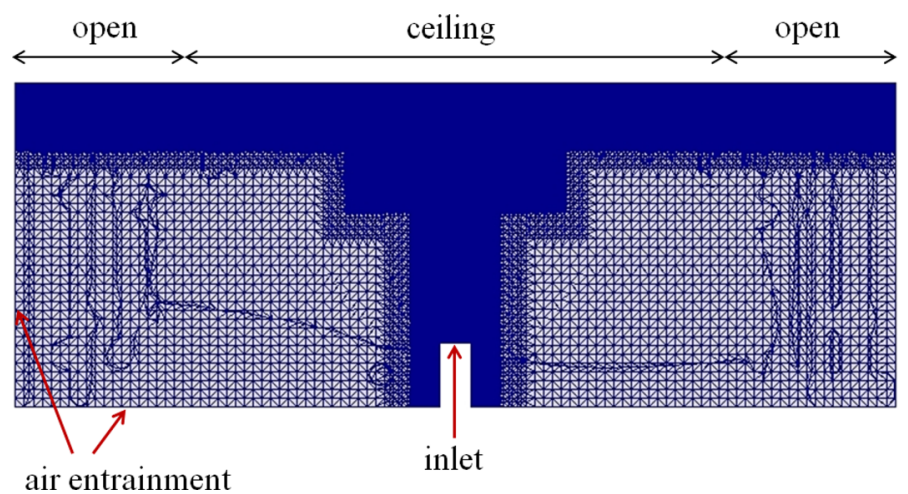

Figure 1. Computational mesh. 


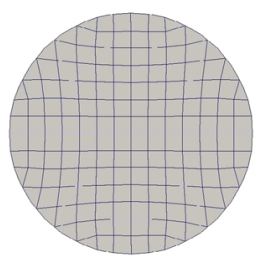

\section{Figure 2. Inlet patch.}

No grid sensitivity study is carried out in the present work. Indeed the grid resolution is deemed sufficient, as illustrated in Sect. 6.1.4. The context of the study is, in other words, restrained to circumstances where the CFD user chooses a mesh that is suitable for LES.

\section{Inlet Boundary Condition}

Based on the test data of Ref. [10], the following velocity profile has been imposed at the inlet:

$$
v=v_{m} \exp \left(-(r / 0.5 D)^{10}\right)
$$

where $V_{m}$ is the maximum value $(5.3 \mathrm{~m} / \mathrm{s}, 4.2 \mathrm{~m} / \mathrm{s}$ and $3.3 \mathrm{~m} / \mathrm{s}), r$ is the radial location and $D$ is the diameter of the nozzle. Although profile (9) has been measured at a distance of around $20 \mathrm{~mm}$ from the duct exit, it has been imposed at the inlet here. In doing so, the velocity at the wall of the nozzle is also set to zero.

The method of random spots is used to excite the flow at the inlet [23], in which velocity fluctuations are superimposed onto the mean velocity based on the idea of turbulent flow being a motion of turbulent spots of a certain size arising at random positions at random times. At each time instant, $M$ spots are randomly placed in the space, with every $i$ th spot having distribution of a component of the velocity fluctuation $f\left(x-x_{r i}^{(n)}\right)$ [23], where $x_{r i}^{(n)}$ is the center of the $i$ th spot. The velocity fluctuation at the $n$th time instant $v^{n}$ is calculated as the sum of fluctuations produced by each spot:

$$
v^{n}(x)=\sum_{i=1}^{M} r_{i}^{n} f\left(x-x_{r i}^{(n)}\right)
$$

where $r_{i} \in[-1,1]$ are random numbers and $x_{r i}$ is random position of spots.

In order to generate velocity fluctuations at the inlet with this method, three parameters must be prescribed: (1) the velocity components, (2) the turbulent stresses, and (3) the eddy length scale. 


\section{Table 2}

Overview of Parameter Variations in the Simulations

\begin{tabular}{lccc}
\hline Case no. & Turbulence intensity & Size of eddies & $c_{k}$ \\
\hline 1 & $2 \%$ & 6 & 0.05 \\
2 & - & - & 0.03 \\
3 & $2 \%$ & 6 & 0.03 \\
4 & $2 \%$ & 12 & 0.03 \\
5 & $10 \%$ & 6 & 0.03 \\
6 & - & - & 0.0 \\
\hline
\end{tabular}

\section{Results and Discussions}

An extensive study is carried out first for the $2.6 \mathrm{~kW}$ hot air jet plume to study the influence of different parameters on the plume evolution and the induced ceiling flows. Afterwards, based on the results obtained for the $2.6 \mathrm{~kW}$ case, additional simulations are also discussed for the other two experiments, HRRs $=2.1$ and $1.6 \mathrm{~kW}$.

\subsection{6 kW Hot Air Jet Plume}

6.1.1. Parameter Variation Six simulations have been carried out to study the effect of the turbulence intensity imposed at the inlet, the turbulence model constant $c_{k}$ and the size of eddies on the plume evolution and the resulting ceiling flow, as listed in Table 2. For all cases $\operatorname{Pr}_{t}=0.7$. For Case $1, c_{k}$ has been set to $c_{k}=0.05$ (corresponding to Smagorinsky constant, $c_{s}=\left(c_{k} \sqrt{\frac{c_{k}}{c_{\varepsilon}}}\right)^{1 / 2}=0.1$

For cases 2 to $5, c_{k}=0.03$ has been chosen, corresponding to $c_{s}=0.07$. These values are within the ranges for $c_{s}$ mentioned in the literature $[25,26]$.

The influence of the SGS model was further studied in Case 6 where no SGS model $\left(c_{k}=0\right)$ is used, i.e., using only the numerical dissipation as dissipation for turbulence. A turbulence intensity of $2 \%$ is chosen for the numerical simulations, based on the experimental data. In Case 2 no perturbations are added, whereas in Case 5 an intensity of $10 \%$ is used, in order to study the effect of imposing higher fluctuations at the inlet. The size of eddies is chosen to be approximately $7 \%$ of the inlet diameter $(6 \mathrm{~mm})$ [25]. The influence of this parameter is investigated in Case 4, where the eddy length scale is doubled to $12 \mathrm{~mm}$.

An additional simulation is also carried out with the static Smagorinsky model $\left(c_{s}=0.07\right)$ and the results are compared to the one-equation eddy viscosity model $\left(c_{k}=0.03\right.$, corresponding to $\left.c_{s}=0.07\right)$. The results are presented in Appendix 1 .

6.1.2. Flow Field in the Plume Region The air temperature measurements from the experiment are only available at $30 \mathrm{~mm}$ above the hot air nozzle. A fitting function is presented in [11] to simulate the temperature profile at this height

$$
T-T_{0}=\left(T_{m}-T_{0}\right) \exp \left(-(r / 0.57 D)^{10}\right)
$$

where $T_{m}=205^{\circ} \mathrm{C}$ and $T_{0}=20^{\circ} \mathrm{C}$. 


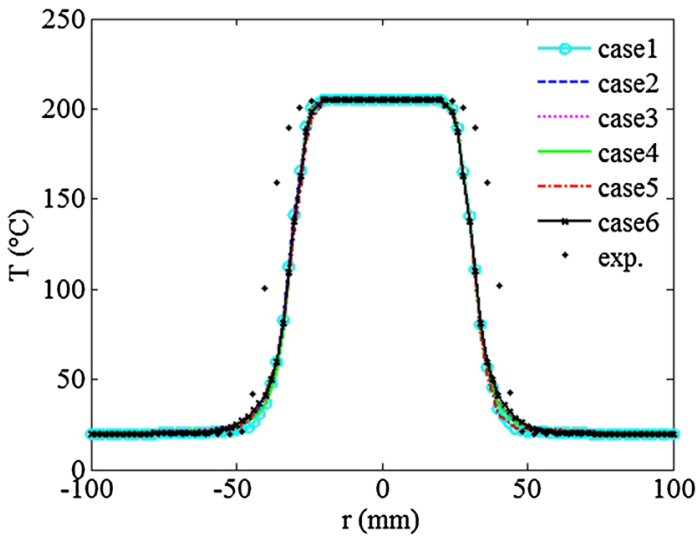

Figure 3. Mean profiles of the temperature $\left({ }^{\circ} \mathrm{C}\right)$ at $\mathrm{z}=30 \mathrm{~mm}$.

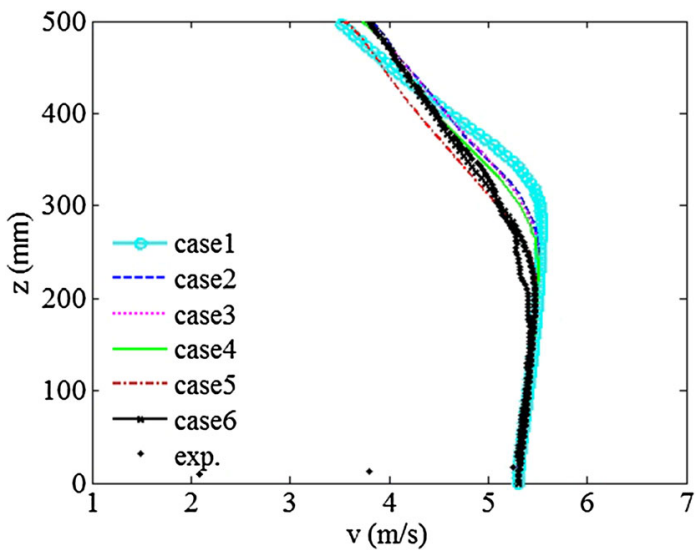

Figure 4. Evolution of mean vertical velocity $(\mathrm{m} / \mathrm{s})$ along the plume axis. See Table 2 for the specific features for each case.

The comparison between the fitting curve for the measured averaged temperature and the predicted results at $z=30 \mathrm{~mm}$ are shown in Figure 3. For all cases the peak value of $205^{\circ} \mathrm{C}$ is well predicted but the profiles are slightly narrower than the measured one.

The evolution of the mean axial velocity along the plume axis is displayed in Figure 4. For all cases, the global trend is similar to the experiment: a slight increase in centerline velocity due to buoyancy acceleration, followed by an abrupt decay due to turbulent mixing with the surrounding air. For Case 1, the breakdown of the plume occurs later due to the higher value of $c_{k}$, which increases the SGS viscosity (Eq. (6)) and reduces turbulence in the near-field of the plume (see Figure 6 below). Decreasing $c_{k}$, results in a faster break-down of the plume. Cases 2-4 provide very similar results: later break-down of the plume compared to the 


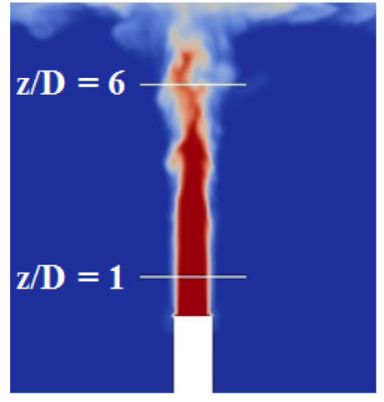

(a)

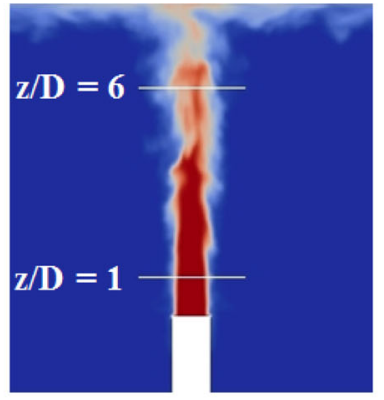

(b)

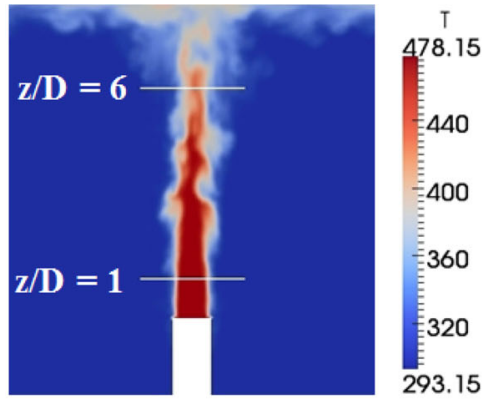

(c)

\section{Figure 5. Illustration of the plume break-down through instanta- neous plume temperature contours (K) for (a) Case 1, (b) Case 3, and (c) Case 5.}

experiment and reasonably good agreement with the measured velocity at heights above $350 \mathrm{~mm}$. Imposing larger eddies at the inlet results in a slightly faster decay due to somewhat stronger turbulence (Figure 6 below), but the effect is not significant. Increasing the turbulence fluctuations to $10 \%$ results in a faster break-down of the plume and therefore lower velocities than the other cases. Case 6, in which no SGS model is used, also reveals faster break-down of the plume and good agreement with the measured data especially after heights above $300 \mathrm{~mm}$. Figure 5 presents instantaneous plume temperature contours for Cases 1, 3 and 5, confirming the above. Figure 6 displays radial profiles of averaged axial velocities, the turbulent radial and axial velocities and the shear stresses at height $z=1 \mathrm{D}$. The symbols denote experimental data. Figure 6a reveals that for all cases a top-hat velocity profile with peak value of $5.3 \mathrm{~m} / \mathrm{s}$ is predicted. The experimental profiles are slightly asymmetric. They are also wider than the calculated ones. This is due to imposing the experimental velocity profile from $z=20 \mathrm{~mm}$ as inlet profile and setting $\mathrm{v}=0$ at the wall of the nozzle in the simulations. This influence was also observed in the temperature profiles (Figure 3).

Figure $6 \mathrm{~b}-\mathrm{d}$, reveal under-prediction of the turbulent velocities and shear stresses with $c_{k}=0.05$ (Case 1). Decreasing $c_{k}$ results in higher values. Again Cases 24 reveal very similar results. As expected, by imposing higher fluctuations (Case 5), higher turbulent velocities and shear stresses are predicted. This is in line with a faster break-down of the plume, as shown in Figure 4. Using no SGS viscosity results in significantly higher turbulent velocities and shear stresses compared to the other cases, due to a lower total viscosity near the inlet. Consequently, there is indeed less damping of the turbulent kinetic energy. Except for Case 1, the turbulent axial velocity fluctuations are well predicted (noticing some over-prediction for Case 6). However, except for case 6, the radial fluctuations are significantly under-predicted, as are the turbulent shear stresses. In terms of turbulent velocities4 and turbulent shear stresses, Case 6 (i.e., no SGS model) yields the best agreement with experiemntal data. As in Figure 4, Case 1 provides the poorest results, indicating that $c_{k}$ is too high. 

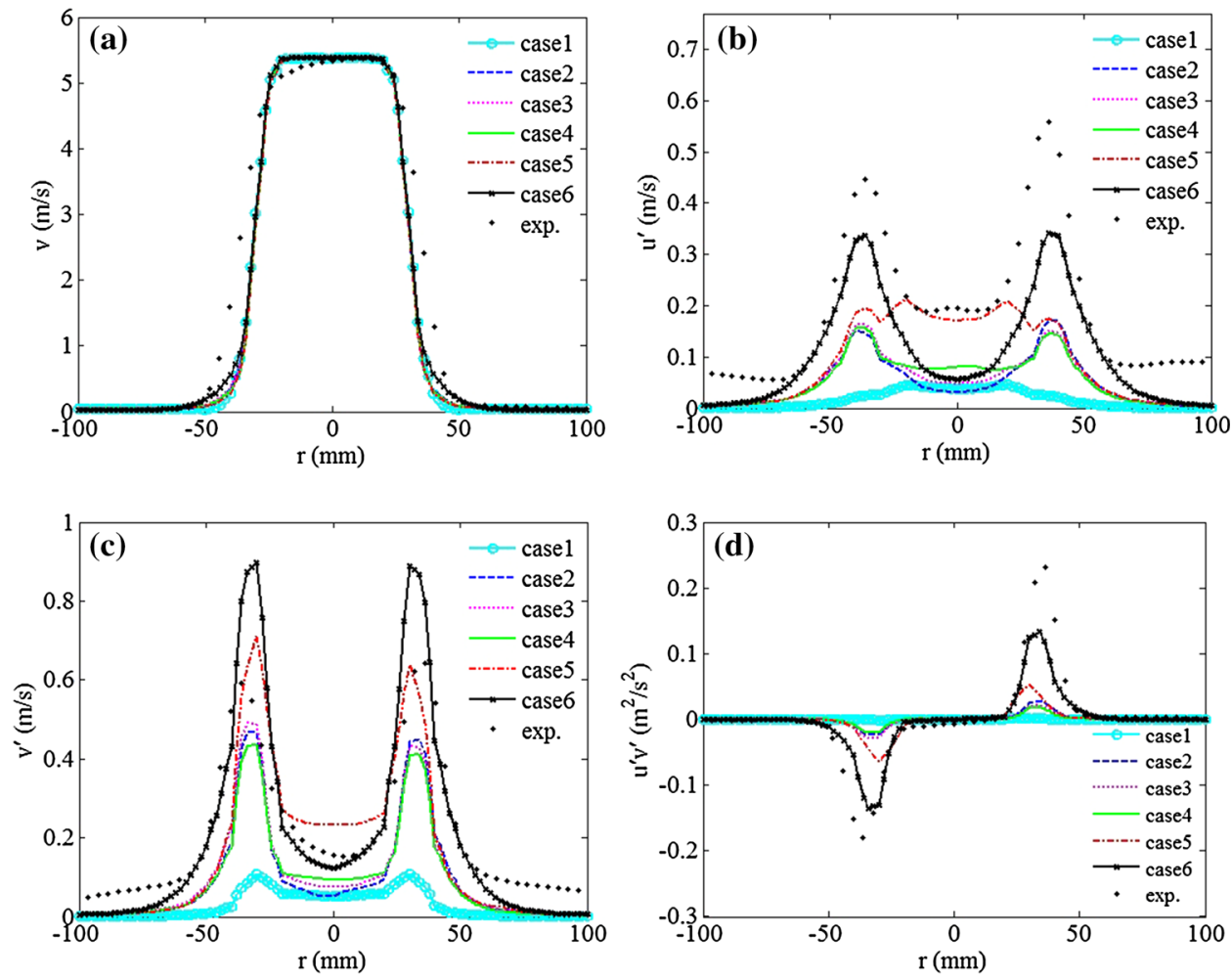

\section{Figure 6. Mean profiles of (a) vertical velocity (m/s), (b) turbulent radial velocity fluctuation, (c) turbulent vertical velocity fluctuation, and (d) turbulent shear stresses at $z / D=1$.}

Figure 7 presents the same results at $\mathrm{z} / \mathrm{D}=6$. As expected from Figure 4 , the peak mean velocity is under-predicted in Case 5. Cases 2 to 4 and Case 6 lead to similar mean axial velocity profiles, in good agreement with the experimental measurements (although the experimental profiles are still wider, as explained above). Case 1 also reveals similar results (good agreement with the experimental data). This is however, only by coincidence, since $\mathrm{z} / \mathrm{D}=6$ is the height where the lines cross in Figure 4. Figures $7 b-d$ indeed conforms that Case 1 provides the poorest agreement to experimental for turbulence. Again, this is due to the too high $c_{k}$ value. All other cases yield very similar results, again slightly better agreement for Case 6 (in particular for the turbulent radial velocity). An over-prediction of approximately 10, 20 and 17\% for the radial and vertical turbulent velocities and shear stresses, respectively, is observed.

6.1.3. Ceiling Jet Flow Figure 8 depicts the mean ceiling layer horizontal velocities from $z=490 \mathrm{~mm}$ to $z=590 \mathrm{~mm}$ at 4 different radial locations, $r$. Similarly to the experiment, the maximum radial velocity decreases with radial distance 

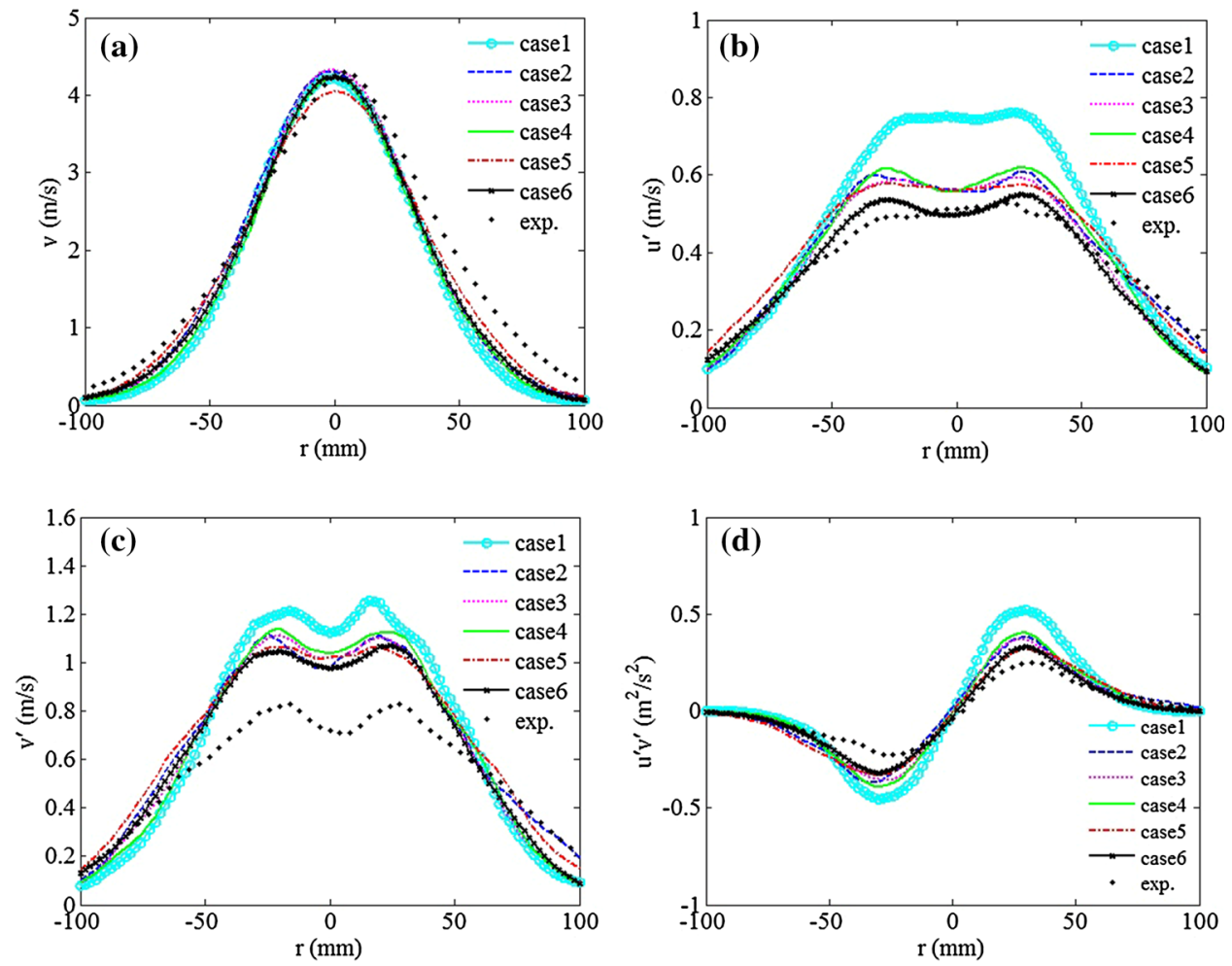

\section{Figure 7. Mean profiles of (a) vertical velocity ( $\mathrm{m} / \mathrm{s})$, (b) turbulent radial velocity fluctuation, (c) turbulent vertical velocity fluctuation, and (d) turbulent shear stresses at $z / D=6$.}

from the center of the ceiling. At $r=100 \mathrm{~mm}$, simulation results are slightly lower than the experimental data. At $r=200 \mathrm{~mm}$ and $r=300 \mathrm{~mm}$, on the other hand, some over-prediction is observed in the region $550 \mathrm{~mm}<\mathrm{z}<580 \mathrm{~mm}$. The maximum velocities for all simulations are lower than the experiments (by approximately $3-11 \%$ ). For Case 6 at $r=300 \mathrm{~mm}$ and $r=400 \mathrm{~mm}$, good agreement with the maximum velocity is observed, albeit a bit further away from the ceiling. Similar peak velocities are calculated in Cases 2 to 4 . Increasing the turbulence intensity at the inlet results in a slightly lower velocity near the ceiling. The velocity reduction due to an increase in $c_{k}$ (Case 1) is more significant though: the increased turbulence near the ceiling (Figure 7) makes the boundary layer thicker. In line with the above, Case 1 yields the poorest agreement with experimental data, indicating the too high value for $c_{k}$.

Figure 9 presents the evolution of the maximum velocities as function of radial position. The correlations developed by Alpert [27] and Heskestad and Yao [27] for the prediction of steady ceiling jet flows beneath un-obstructed ceilings are shown for comparison purposes only. All graphs show the same trend, i.e., the velocity decreases with radial distance. However, the Froude number for both 

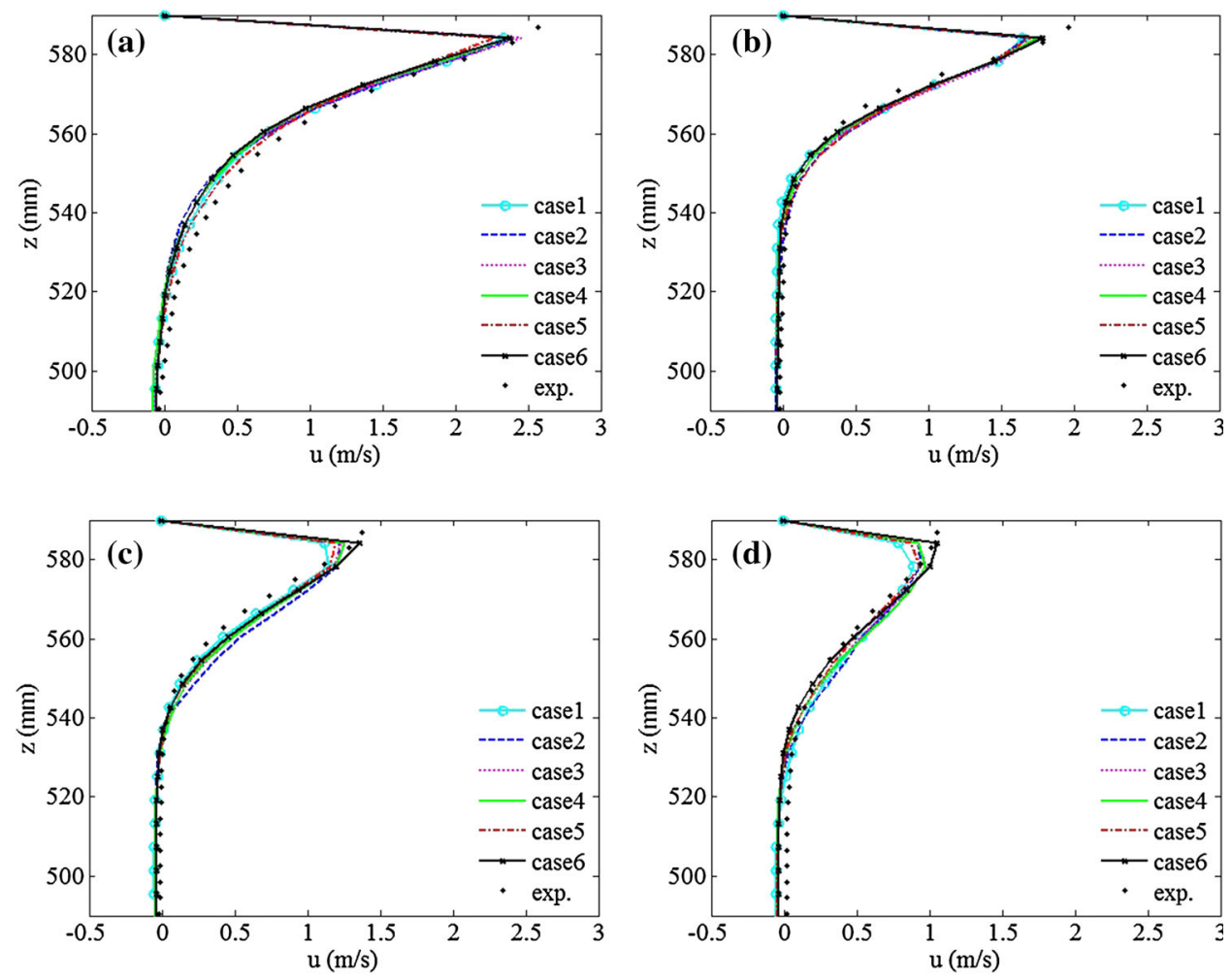

Figure 8. Mean ceiling layer horizontal velocities at different radial
locations: (a) $100 \mathrm{~mm}$, (b) $200 \mathrm{~mm}$, (c) $300 \mathrm{~mm}$, and (d) $400 \mathrm{~mm}$.

experiments in [27] was much lower than here, which explains the lower velocity values in the correlations. Good agreement between the measured and calculated velocities. It should, however, be noted that the maximum velocities for the experiment are at $z=587 \mathrm{~mm}$ (the highest available measurement point), whereas in the simulations the maximum occurs at different heights. While the experimental data suggest the thickness of the viscous sublayer to be at most $\delta_{V_{\max }}=3 \mathrm{~mm}$, in the simulations this thickness varies, for example in Case 5 , from $\delta_{V_{\max }}=4 \mathrm{~mm}$ at $r=57.6 \mathrm{~mm}$ to $\delta_{V_{\max }}=12 \mathrm{~mm}$ at $r=552.6 \mathrm{~mm}$.

6.1.4. LES Resolution The ratio of the turbulent to laminar viscosity $\mu_{t} / \mu$ is shown in Figure 10. The maximum value of the ratio is 2.6, observed in Cases 1 and 5, whereas for the other cases the ratio is below 1. For Case 1, this is due to the higher value for $c_{k}$ (see Eq. (6)). For Case 5, this is due to the higher level of turbulent fluctuations at the inlet. Indeed an evolution is observed towards the values for Cases 2-4 at higher heights. Overall, the added turbulent viscosity from the turbulence model is of the same order of magnitude as the molecular viscosity 


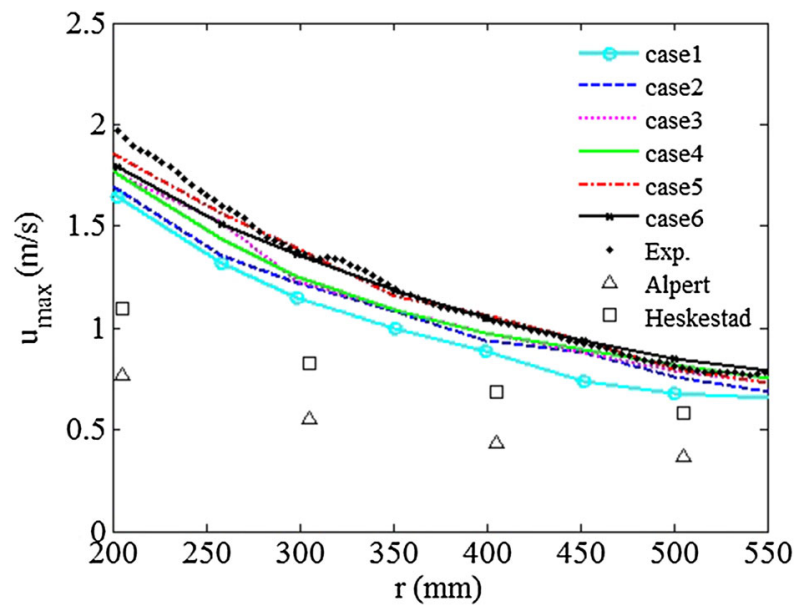

Figure 9. Comparison of the measured and simulated maximum ceiling velocity. Values from correlations [27] are added for comparison purposes only. Note: the position of maximum velocity in the experiment is closer to the ceiling than in the simulations.

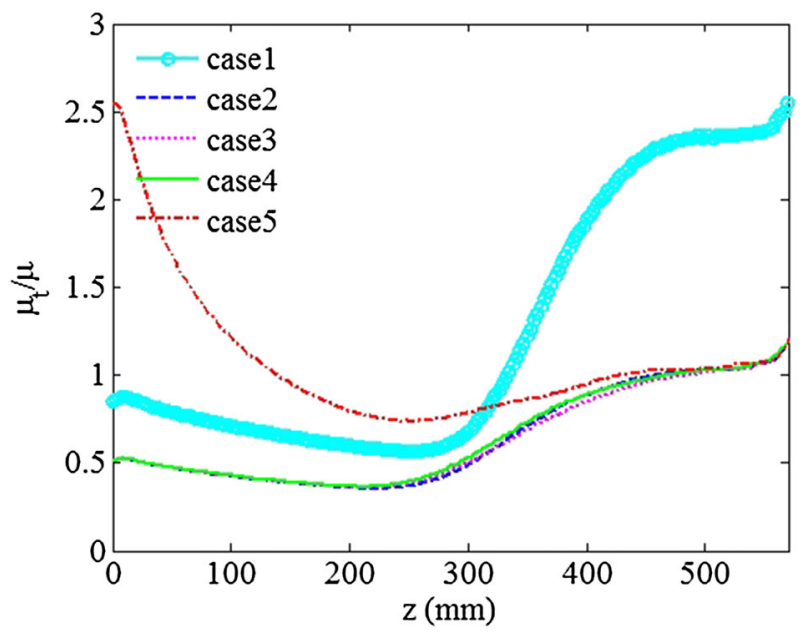

\section{Figure 10. The ratio of turbulent to laminar viscosity $\mu_{f} / \mu$ on the centerline.}

(small influence of the SGS model), indicating that the LES grid is fine enough to accurately simulate all cases.

Figure 11 presents the same results along the ceiling at $z=570 \mathrm{~mm}$. The ratio is the highest for Case 1, as was expected from Figure 10, again due to the higher value for $c_{k}$. The other cases reveal similar results with the maximum value of the ratio less than 1.1 (at the plume's centerline) and below 0.8 at further radial distances, again illustrating the good grid resolution. 


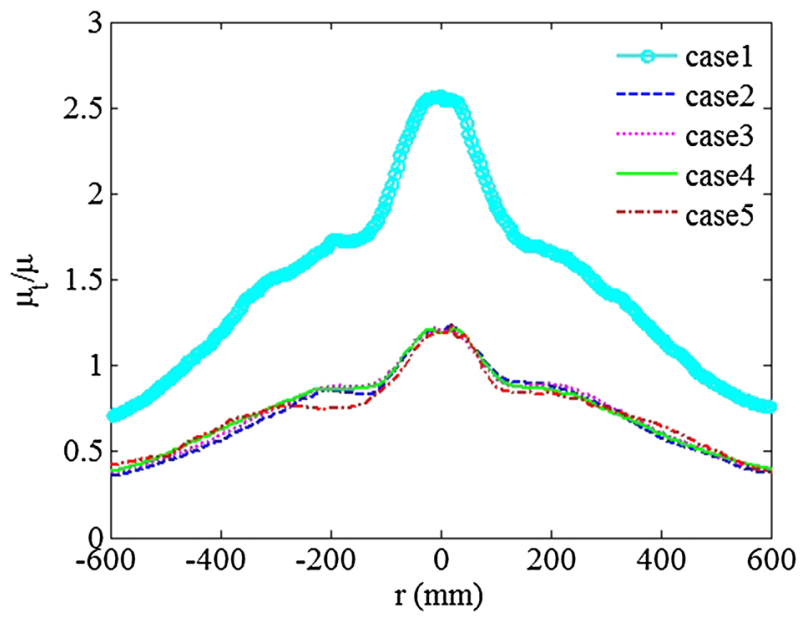

Figure 11. Turbulence resolution along the ceiling.

\section{Table 3}

\section{Overview of the Simulations}

\begin{tabular}{lcccc}
\hline $\mathrm{Q}_{\text {conv. }}(\mathrm{kW})$ & $\mathrm{v}_{\mathrm{i}, \max }(\mathrm{m} / \mathrm{s})$ & Turbulence intensity & Size of eddies & $\mathrm{c}_{\mathrm{k}}$ \\
\hline 2.1 & 4.2 & $4 \%$ & 6 & 0.03 \\
2.1 & 4.2 & - & - & 0.0 \\
1.6 & 3.3 & $5 \%$ & 6 & 0.03 \\
1.6 & 3.3 & - & - & 0.0 \\
\hline
\end{tabular}
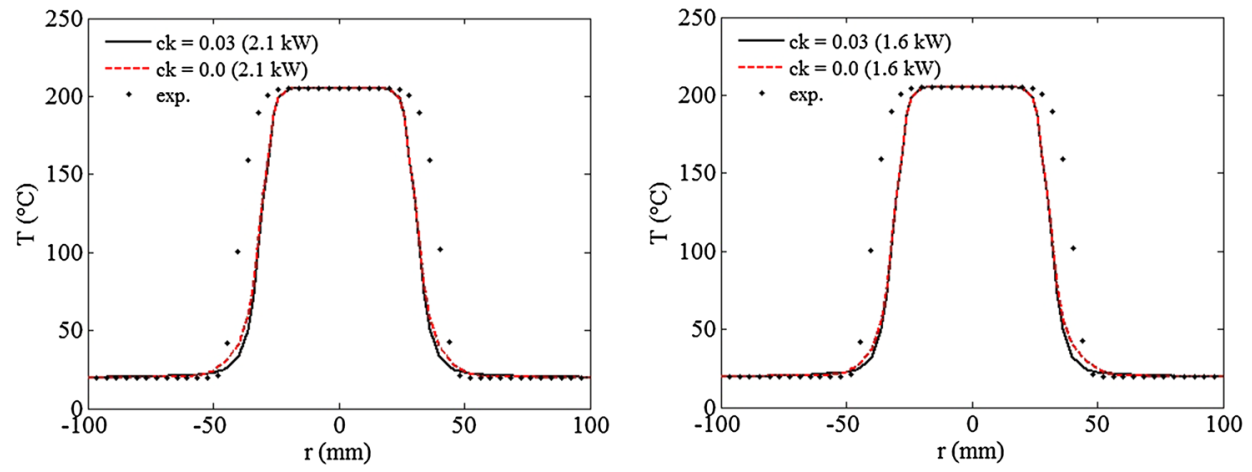

Figure 12. Mean profiles of the temperature $\left({ }^{\circ} \mathrm{C}\right)$ at $z=30 \mathrm{~mm}$ : $2.1 \mathrm{~kW}$ (left), and $1.6 \mathrm{~kW}$ (right).

\subsection{1 and 1.6 $\mathrm{kW}$ Hot Air Jet Plumes}

Additional numerical studies have also been carried out for hot air jet plumes with convective HRRs of $2.1 \mathrm{~kW}\left(v_{i, \max }=4.2 \mathrm{~m} / \mathrm{s}\right)$ and $1.6 \mathrm{~kW}\left(v_{i, \max }=3.3 \mathrm{~m} /\right.$ 

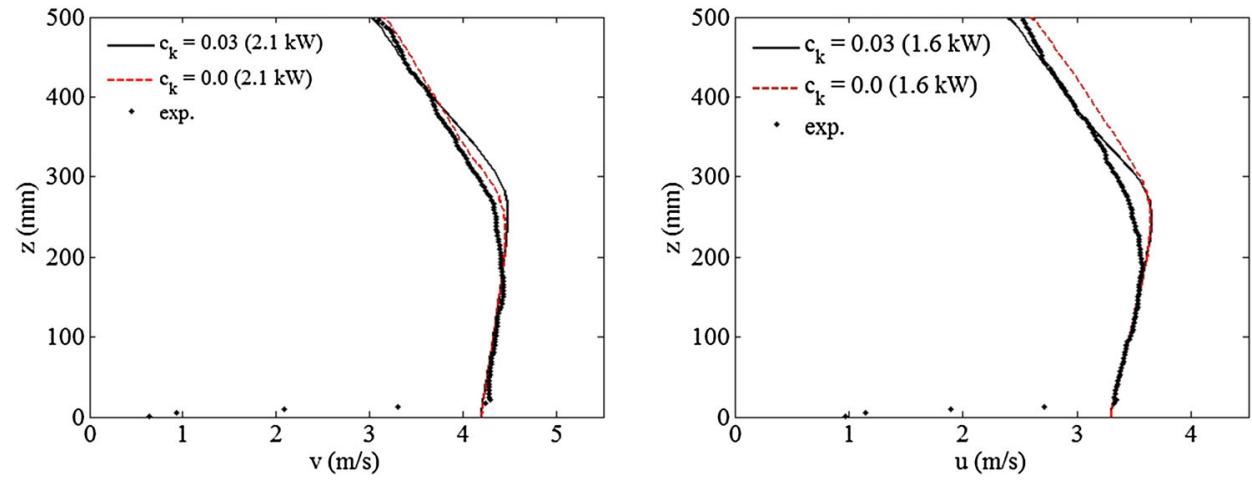

Figure 13. Evolution of mean vertical velocity $(\mathrm{m} / \mathrm{s})$ along the plume axis: $2.1 \mathrm{~kW}$ (left), and $1.6 \mathrm{~kW}$ (right).
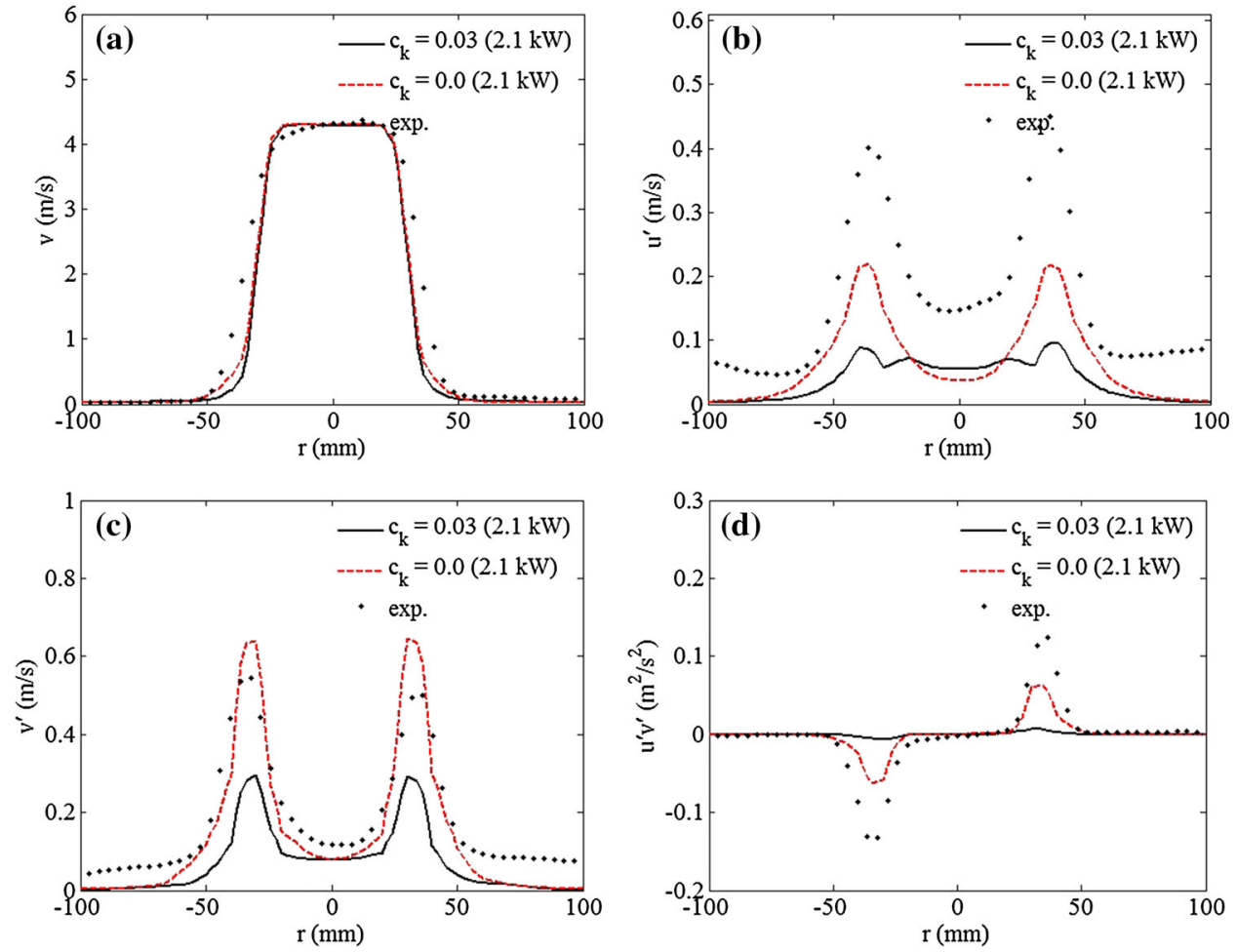

Figure 14. Mean profiles of (a) vertical velocity (m/s), (b) turbulent radial velocity fluctuation, (c) turbulent vertical velocity fluctuation, and (d) turbulent shear stresses at $z / D=1$ for $2.1 \mathrm{~kW}$ case. 
s). Two sets of simulations are chosen for each case: one with SGS model $\left(c_{k}=0.03\right)$ and the turbulence intensity taken from the experimental data (similar to Case 3 in the previous section) and another one without SGS model $\left(c_{k}=0.0\right)$, in order to investigate whether similar results as the $2.6 \mathrm{~kW}$ case will be predicted. For all simulations, $P r_{t}=0.7$ and the size of eddies is set to $6 \mathrm{~mm}$. The list of simulations is presented in Table 3 .

6.2.1. The Plume Region The predicted mean temperature profiles at $\mathrm{z}=30 \mathrm{~mm}$ and their comparison with the measured temperature (Eq. (11)) for both cases are shown in Figure 12. The peak temperature is well predicted. However, as explained before, the profiles are slightly narrower than the measured ones.

The evolution of the mean axial velocities is presented in Figure 13. For $2.1 \mathrm{~kW}$ case, using no SGS viscosity at the inlet results in a slightly faster break-down of the plume and better agreement with the experimental data.

Both cases for the $1.6 \mathrm{~kW}$ hot air plume predict the same height for the plume's break-down. This is different from what was observed in Figure 4. Note, however, that the turbulence intensity at the inlet, chosen in agreement with experimental
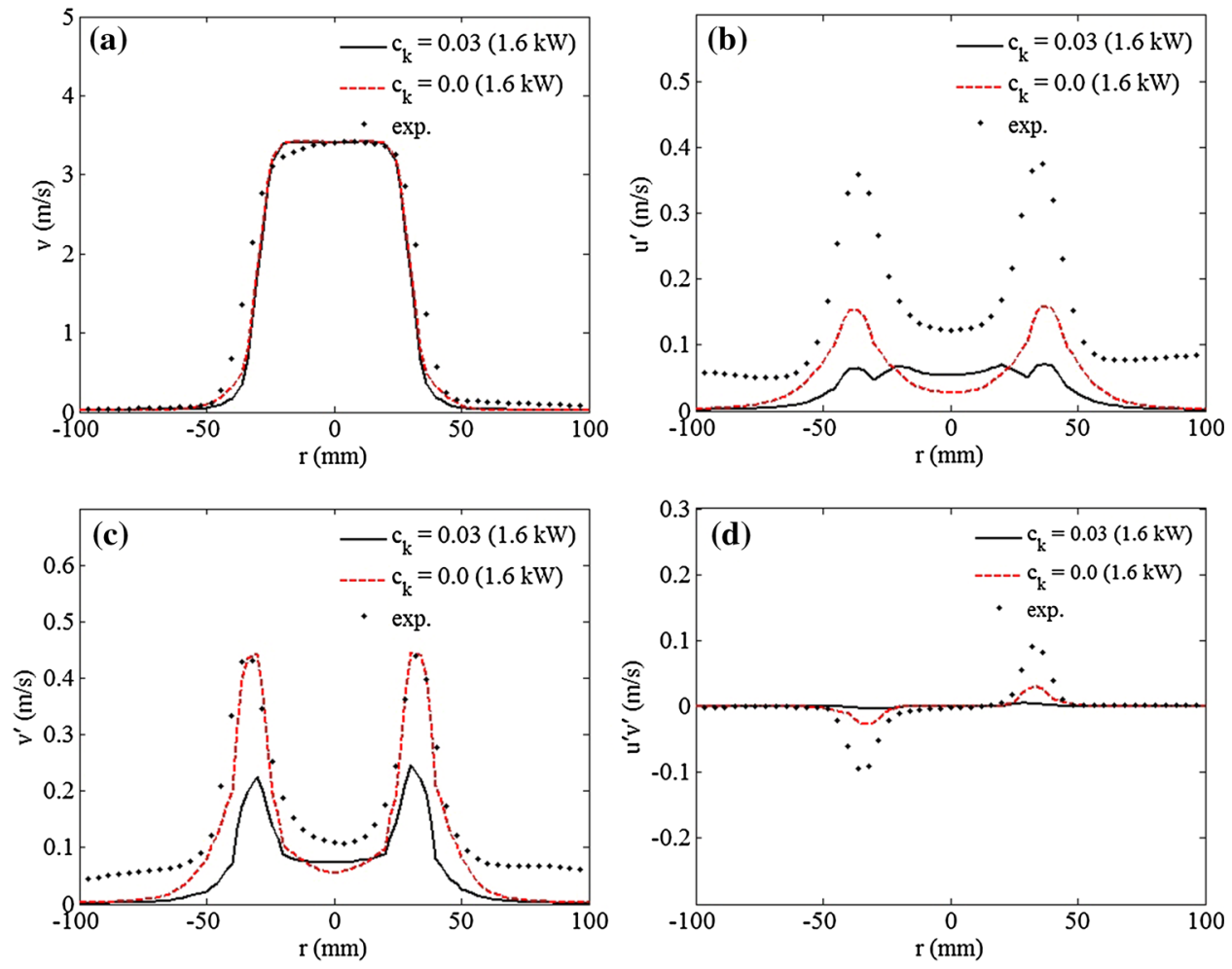

Figure 15. Mean profiles of (a) vertical velocity (m/s), (b) turbulent radial velocity fluctuation, (c) turbulent vertical velocity fluctuation, and (d) turbulent shear stresses at $\mathrm{z} / \mathrm{D}=1$ for $1.6 \mathrm{~kW}$ case. 
data, is 2.5 times higher here at the inlet (5\% vs. $2 \%)$. Figure 4 reveals that an increase in turbulence intensity leads to faster break-down of the plume, explaining the observation made. The decay of the centerline velocity is better predicted without SGS model (the decay is too fast with $c_{k}=0.03$ ). Thus, in line with the above, the results without SGS model are globally in better agreement with experimental data.

The radial profiles of averaged axial velocities, the turbulent radial and axial velocities and shear stresses at $\mathrm{z} / \mathrm{D}=1$ are shown in Figs. 14 and 15, respectively. Both cases reveal good prediction for the peak mean vertical velocities for $c_{k}=0.0$ and 0.03 . Figures $14 \mathrm{~b}-\mathrm{d}$, and $15 \mathrm{~b}-\mathrm{d}$ reveal higher values of turbulent velocities and shear stresses with $c_{k}=0$, in line with what was observed for the $2.6 \mathrm{~kW}$ case. Again, for all cases under-prediction of turbulent velocities and shear stresses, compared to the experimental data, is observed (except for the vertical turbulent velocities for $c_{k}=0$ ).

Figures 16 and 17 depict the same results at $z / D=6$. A slight over-prediction of the maximum mean vertical velocities for $c_{k}=0$ is seen (Figs. 16 (a) and 17 (a)), in line with Figure 13.
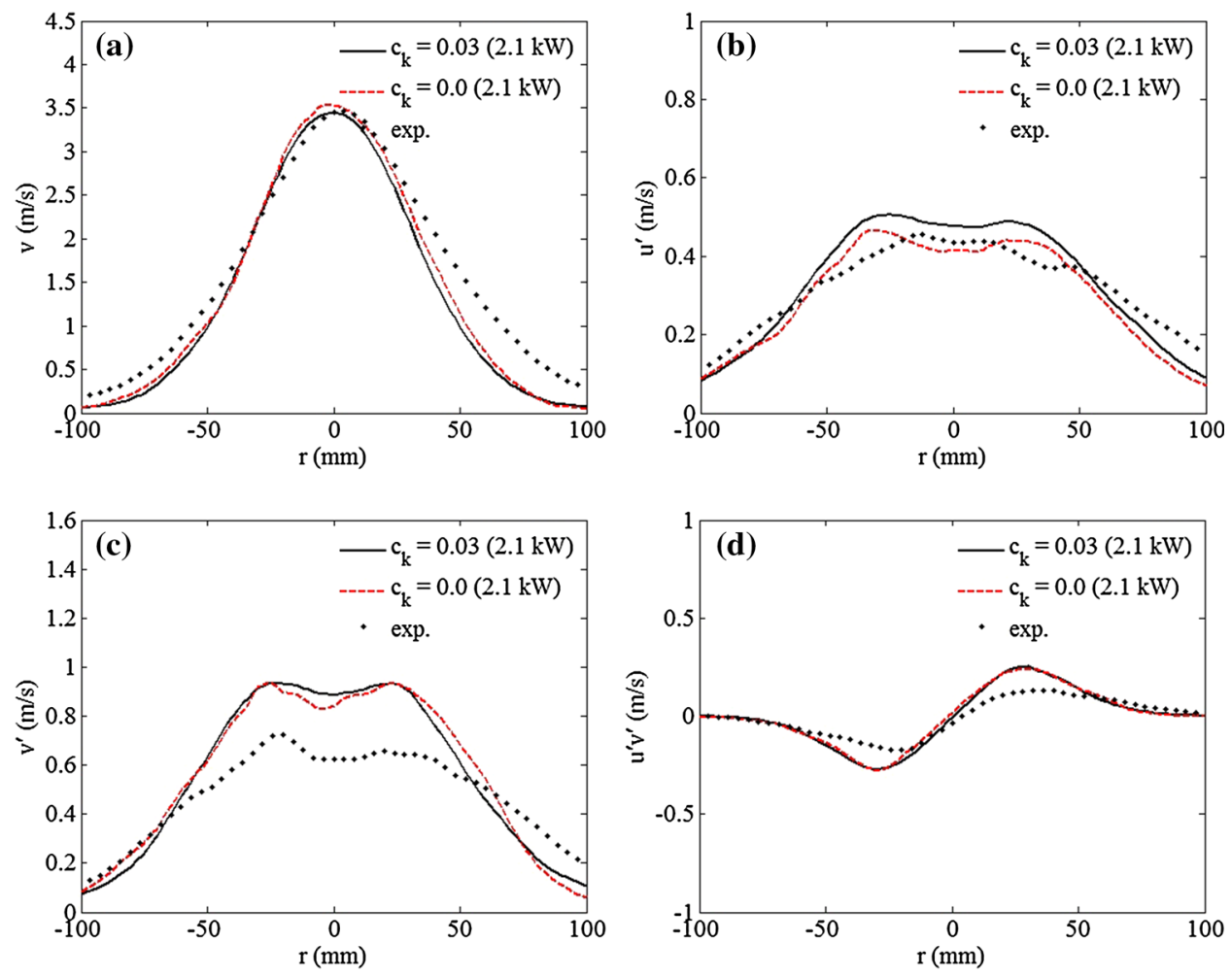

Figure 16. Mean profiles of (a) vertical velocity (m/s), (b) turbulent radial velocity fluctuation, (c) turbulent vertical velocity fluctuation, and (d) furbulent shear stresses at $z / D=6$ for $2.1 \mathrm{~kW}$ case. 

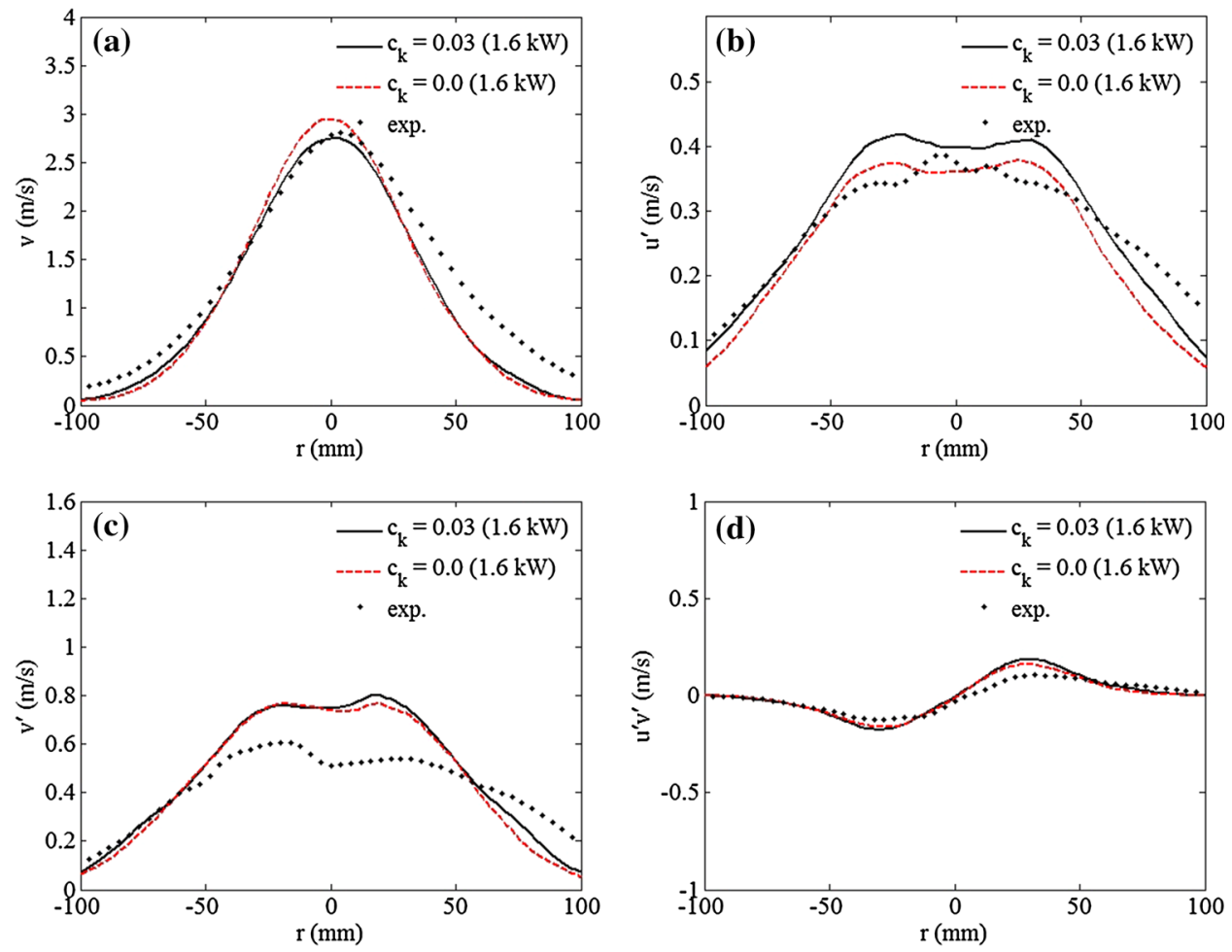

\section{Figure 17. Mean profiles of (a) vertical velocity (m/s), (b) turbulent radial velocity fluctuation, (c) turbulent vertical velocity fluctuation, and (d) turbulent shear stresses at $z / D=6$ for $1.6 \mathrm{~kW}$ case.}

Except for turbulent radial velocities, no significant difference is observed between the results for $c_{k}=0$ and 0.03 for both jet plumes, as was also the case for the $2.6 \mathrm{~kW}$ jet plume.

6.2.2. Ceiling Jet Flow Figures 18 and 19 present the mean ceiling layer horizontal velocities from $z=490 \mathrm{~mm}$ to $z=590 \mathrm{~mm}$ at 4 different radial locations, $r$. The same trend as the experiment is seen in the predicted results: decrease of the radial velocity with radial distance from the center of the ceiling. In line with the $2.6 \mathrm{~kW}$ case, a slight under-prediction of the velocity profile at $r=100 \mathrm{~mm}$ for both plumes is observed. At $r=300$ and $400 \mathrm{~mm}$ the simulations with $c_{k}=0$ reveal higher prediction of the maximum radial velocities and therefore, better agreement with the experimental data.

\section{Conclusions}

Large eddy simulations of a thermal jet plume under a horizontal ceiling and the induced ceiling flow have been performed. The influence of the turbulence intensity, the size of eddies and the constant used in the SGS eddy viscosity model 

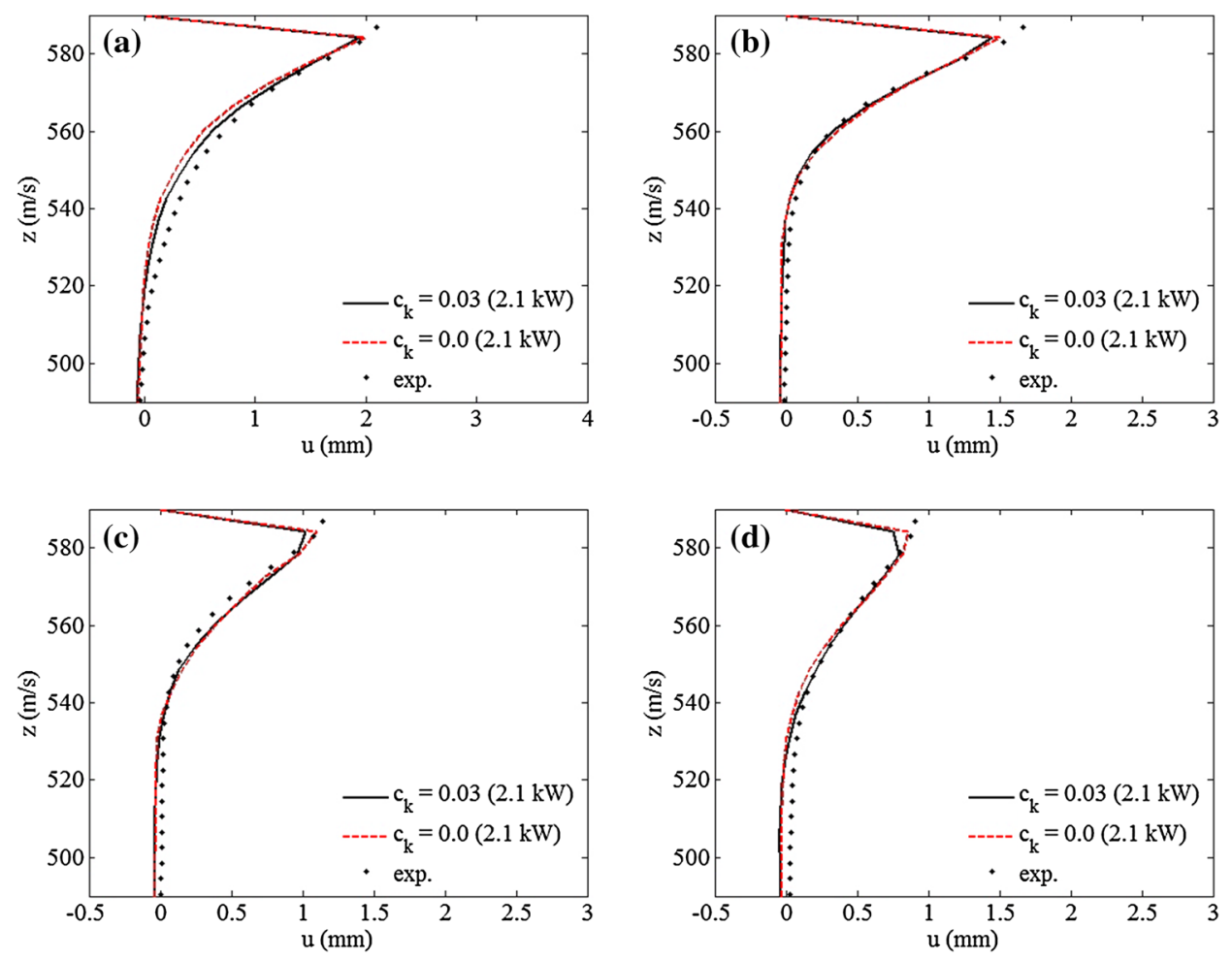

\section{Figure 18. Mean ceiling layer horizontal velocities at different radial locations: (a) $100 \mathrm{~mm}$, (b) $200 \mathrm{~mm}$, (c) $300 \mathrm{~mm}$, and (d) $400 \mathrm{~mm}$ for $2.1 \mathrm{~kW}$ case.}

have been examined. For the cases considered, the size of eddies imposed at the inlet has little influence on the results. The SGS model constant $c_{k}$ and, to a lesser extent, imposing high fluctuations at the inlet, are important in the prediction of the plume's evolution and the ceiling flow velocities. The value $c_{k}=0.05$ is too high. For the cases considered, the numerical studies without SGS model are in better agreement with the experimental data. It is stressed that these observations are made in the context of good grid resolution for LES.

The results demonstrated that FireFOAM is capable of predicting well the mean values in the plume. The velocity fluctuations and stresses are under-estimated in the near-field $(\mathrm{z} / \mathrm{D}=1)$ region, whereas reasonably good agreement was obtained at higher location $(\mathrm{z} / \mathrm{D}=6)$.

In the ceiling jet region, the maximum velocity is slightly under-predicted and the velocity boundary layer thickness is larger than suggested by the experimental data. In line with the results in the plume region, the results without SGS model are in best agreement with experimental data for the cases considered (with good grid resolution), and $c_{k}=0.05$ is too high.

The observations made prevail for the three different convective heat release rates considered. 

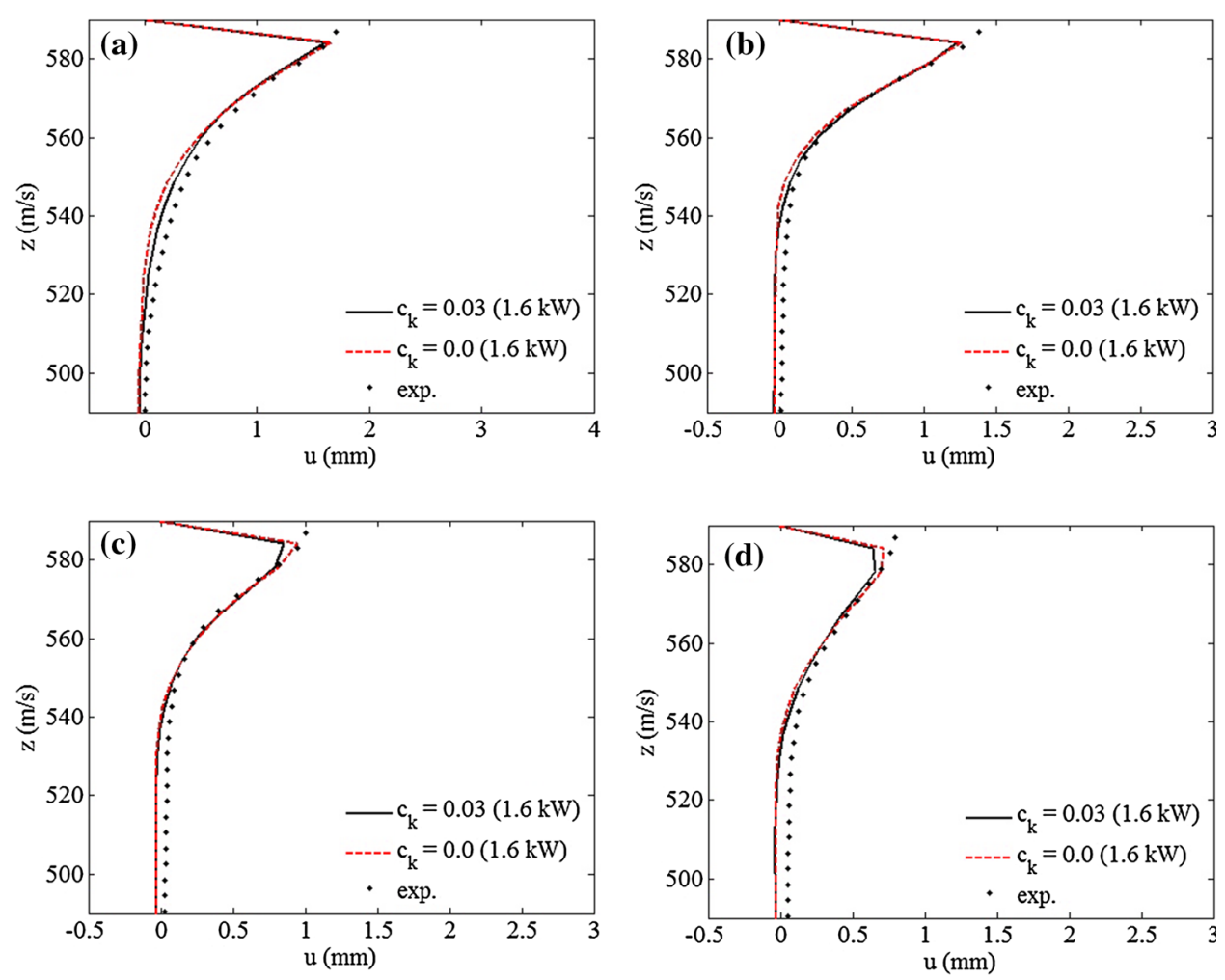

\section{Figure 19. Mean ceiling layer horizontal velocities at different radial locations: (a) $100 \mathrm{~mm}$, (b) $200 \mathrm{~mm}$, (c) $300 \mathrm{~mm}$, and (d) $400 \mathrm{~mm}$ for $1.6 \mathrm{~kW}$ case.}

\section{Acknowledgments}

This research was funded by the Scientific Fund for Research Flanders (Belgium) (FWO-Vlaanderen) through project 3G004912. Dr. Tarek Beji is Postdoctoral Fellow of the Fund of Scientific Research-Flanders (Belgium) (FWO-Vlaanderen). Xiangyang Zhou, Karl V. Meredith, Yi Wang and Prateep Chatterjee from FM Global are gratefully acknowledged for sharing the experimental data and their insightful guidance during this work.

\section{Appendix 1}

The figures in the appendix present the comparison between the measured and predicted results for the one-equation model $\left(c_{k}=0.03\right.$ corresponding to $\left.c_{s}=0.07\right)$ and the static Smagorinsky model $\left(c_{s}=0.07\right)$ for $2.6 \mathrm{~kW}$ case. Figure 20 shows the evolution of the mean vertical velocity along the plume axis. The radial profiles of the averaged axial velocities, the turbulent radial and axial velocities and the shear stresses at heights $z=1 \mathrm{D}$ and $z=6 \mathrm{D}$ are displayed in Figures 21 and 22, respectively. 


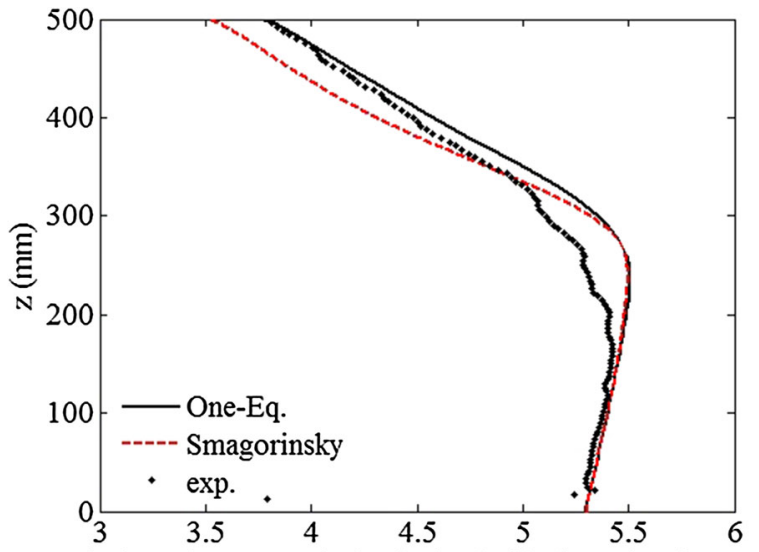

Evolution of mean vertical velocity $(\mathrm{m} / \mathrm{s})$ along the plume axis

Figure 20. Evolution of mean vertical velocity $(\mathrm{m} / \mathrm{s})$ along the plume axis.
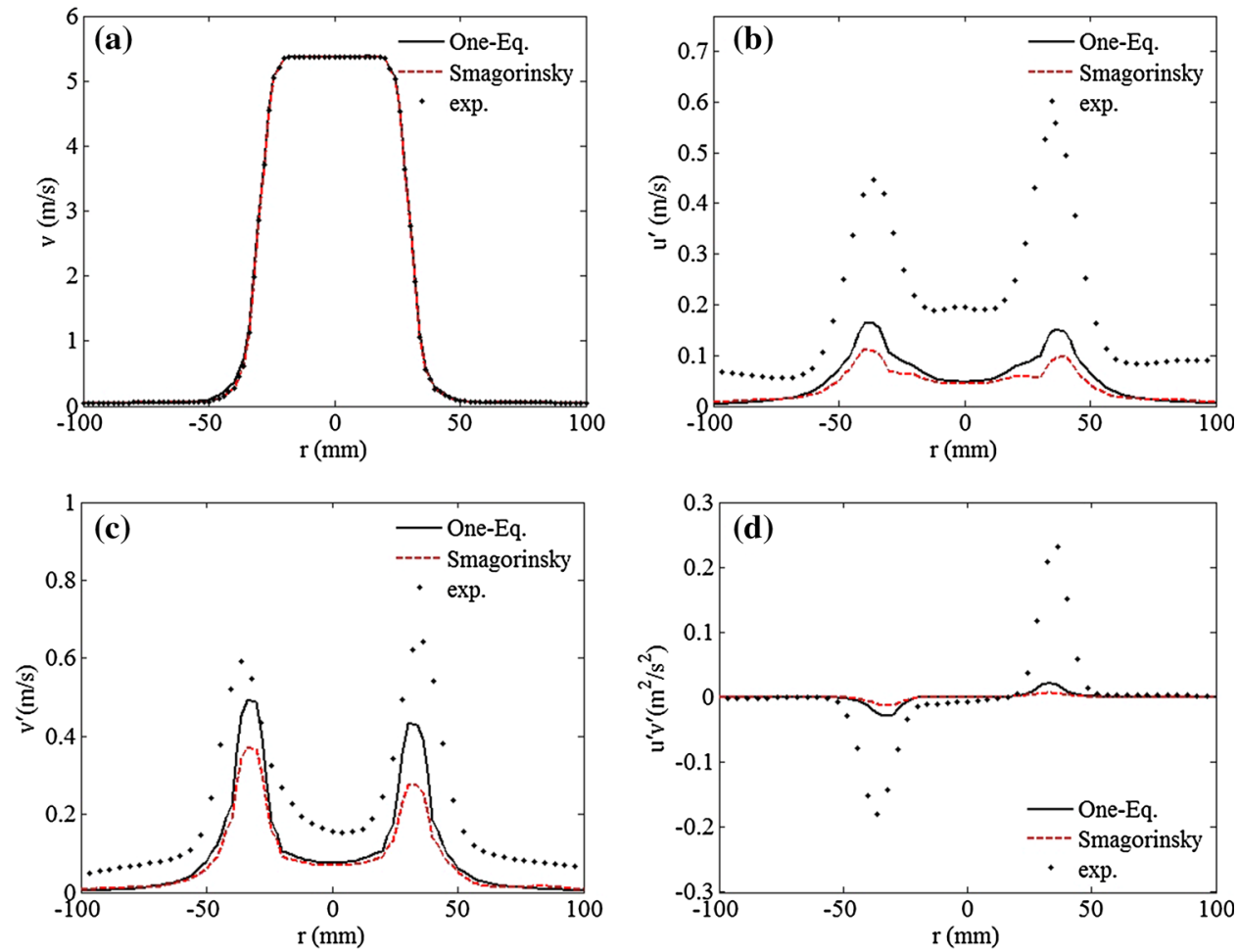

Figure 21. Mean profiles of (a) vertical velocity $(\mathrm{m} / \mathrm{s})$, (b) turbulent radial velocity fluctuation, (c) turbulent vertical velocity fluctuation, and (d) turbulent shear stresses at $z / D=1$. 

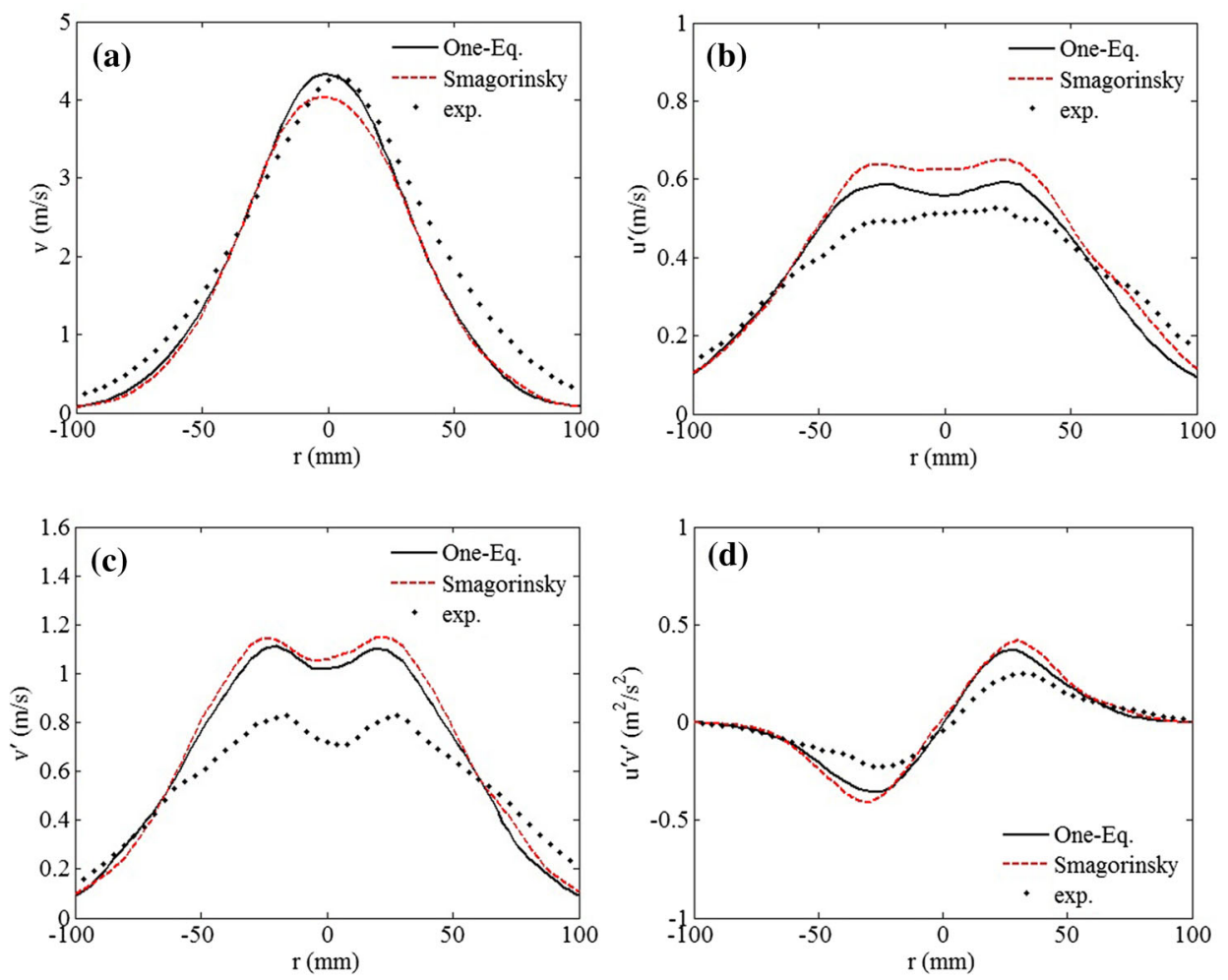

Figure 22. Mean profiles of (a) vertical velocity $(\mathrm{m} / \mathrm{s})$, (b) turbulent radial velocity fluctuation, (c) turbulent vertical velocity fluctuation, and (d) turbulent shear stresses at $z / D=6$.

\section{References}

1. George WK, Alpert RL, Tamanini F (1977) Turbulence measurements in an axisymmetric buoyant plume. Int J Heat Mass Transf 20:1145-1154

2. Shabbir A, George WK (1994) Experiments on a round turbulent buoyant plume. J Fluid Mech 275:1-32

3. Van Maele K, Merci B (2006) Application of two buoyancy-modified k- $\varepsilon$ turbulence models to different types of buoyant plumes. Fire Saf J 41:122-138

4. Zhou X, Luo KH, Williams JJR (2001) Large-eddy simulation of a turbulent forced plume. Eur J Mech B/Fluids 20:233-254

5. Worthy J, Rubini P (2005) A study of LES stress and flux models applied to a buoyant jet. Numer Heat Transf B Fundam 48:235-256

6. Yan ZH (2007) Large eddy simulations of a turbulent thermal plume. Heat Mass Transf 43:503-514

7. Maragkos G, Rauwoens P, Wang Y, Merci B (2013) Large eddy simulations of the flow in the near-field region of a turbulent buoyant helium plume. Flow Turbul Combust 90:511-543 
8. Xin Y, Gore J, McGrattan KB, Rehm RG, Baum HR (2002) Large eddy simulation of buoyant turbulent pool fires. Proc Combust Inst 29:259-266

9. Worthy J, Rubini P (2003) Large eddy simulation of buoyant plumes, 4th International Seminar on Fire and Explosion Hazards, Londonderry, UK

10. Zhou X (2015) Characterization of interactions between hot air plumes and water sprays for sprinkler protection. Proc Combust Inst 35:2723-2729

11. Zhou X (2015) PIV measurments of velocity fields of three hot air jet plumes impinging on a horizontal ceiling, 10th Asia-Oceania Symposium on Fire Science and Technology, Tsukuba, Japan

12. Alpert RL (1975) Turbulent ceiling-jet induced by large-scale fires. Combust Sci Technol 11:197-213

13. You HZ, Faeth GM (1981) An investigation of fire impingement on a horizontal ceiling, Pennsylvania State University, Department of Mechanical Engineering

14. Kung H-C, You H-Z, Spaulding RD (1986) Ceiling flows of growing rack storage fires. Twenty first Symposium (International) on Combustion/The Combustion Institute, pp $121-128$

15. Chatterjee P, Meredith KV, Ditch B, Yu H-Z, Wang YI, Tamanini F (2014) Numerical simulations of strong-plume driven ceiling flows. Fire Saf Sci 11:207

16. FireFOAM 2.2.x. https://github.com/fireFoam-dev/

17. Drysdale D (2011) An introduction to fire dynamics. Wiley, New York

18. OpenFOAM. http://www.openfoam.org/

19. Schumann U (1975) Subgrid scale model for finite difference simulations of turbulent flows in plane channels and annuli. J Comput Phys 18:376-404

20. Yoshizawa A, Horiuti K (1985) A statistically-derived subgrid-scale kinetic energy model for the large-eddy simulation of turbulent flows. J Phys Soc Jpn 54:2834-2839

21. Fureby C, Tabor G (1997) Mathematical and physical constraints on large-eddy simulations. Theoret Comput Fluid Dyn 9:85-102

22. OpenFOAM: The Open Source CFD Toolbox, User Guide, version 2.3.0. February 05, 2014

23. Kornev N, Kröger H, Hassel E (2008) Synthesis of homogeneous anisotropic turbulent fields with prescribed second-order statistics by the random spots method. Commun Numer Methods Eng 24:875-877

24. Sullivan PP, McWilliams JC, Moeng C-H (1994) A subgrid-scale model for large-eddy simulation of planetary boundary-layer flows. Bound-Layer Meteorol 71:247-276

25. Versteeg HK, Malalasekera W (2007) An introduction to computational fluid dynamics: the finite volume method. Pearson Education

26. Pope SB (2000) Turbulent flows. Cambridge University Press, Cambridge

27. Alpert RL (2002) SFPE handbook of fire protection engineering, ceiling jet flows. Springer, Berlin 